\title{
Processing Technology and Experimental Analysis of Gas-assisted Laser Cut Micro Thin Wood
}

\author{
Qingwei Liu, ${ }^{\mathrm{a}, \mathrm{b}}$ Chunmei Yang, ${ }^{\mathrm{a}, \mathrm{b}, *}$ Bo Xue, ${ }^{\mathrm{a}, \mathrm{b}}$ Qian Miao, ${ }^{\mathrm{a}, \mathrm{b}}$ and Jiuqing Liu ${ }^{\mathrm{a} *}$ \\ Unsupported combustion nitrogen $\left(\mathrm{N}_{2}\right)$ and flame-retardant helium $(\mathrm{He})$ \\ were used to facilitate laser-cutting of cherry wood, and the effects of \\ process parameters, gas flow, and gas reactivity on the surface quality of \\ thin wood were studied. Using identical processing parameters, the cherry \\ wood was laser-cut with and without the added gases. Through comparing \\ the cutting width, heat affected zone (HAZ), and surface burning \\ conditions under different gas-assistance conditions, the influence of the \\ added gases on the gasification and combustion of cherry wood was \\ analyzed. When $\mathrm{N}_{2}$ gas was used, the cutting width was less than that of \\ laser direct cutting, but the surface of the burning area did not remarkably \\ improve. Under the same conditions, when He gas was added, the burning \\ areas on both sides of the kerf were remarkably reduced and the \\ consistency of kerf was good. This indicated that He gas had good oxygen \\ isolation and flame-retardant effects. The surface of the kerf was observed \\ with a scanning electron microscope, and addition of He gas remarkably \\ improved the burning that occurred when cutting kerf. This study combined \\ gas processing and laser technology, and it provided technical references \\ for reducing post treatment improving the surface quality of laser- \\ processed wood.
}

Keywords: Gas assisted; Laser cutting; Quality of cutting kerf; Micromorphology

Contact information: a: Northeast Forestry University, College of Mechanical and Electrical Engineering, Harbin, 150040, China; b: Forestry and Woodworking Machinery Engineering Technology Center, Northeast Forestry University, Harbin, 150040, China;

*Corresponding author: ycmnefu@126.com;nefujdljq@163.com

\section{INTRODUCTION}

Laser processing is a non-contact processing method in which a high-power density laser beam irradiates the workpiece and makes it instantly gasify to facilitate drilling, cutting, welding, and other special processing (Naderi et al. 1999; Hovikorpi et al. 2004; Li et al. 2018). Wood has good laser absorption, but the issue of wood surface burning during processing impedes the application of lasers in wood processing (Martin et al. 2005; Fukuta et al. 2016; Alejandro et al. 2017). At the same time, due to serious carbonization phenomenon, the surface roughness was increased, which affected the physical properties and visual beauty of wood (Gaff et al. 2020).

Gurau and Petru (2018) studied the influence mechanisms of different laser parameters on processing quality and determined the mathematical relationship between wood surface roughness and laser parameters. Eltawahni et al. (2011) proposed a process parameter selection method for medium-density fiberboard (MDF) laser cutting used to determine the influence of various factors on quality indicators. 
Barcikowski et al. (2006) described the temperature and heat affected zone (HAZ) of the $\mathrm{CO}_{2}$ laser-cutting process and changed the materials and technological parameters to control the damage width caused by laser cutting. Jiang et al. (2016) analyzed wood surface quality after laser-cutting in relation to changes in laser energy and wood type. Yang et al. (2018) analyzed the influence of the ablative mechanism of wood processed with a nanosecond laser on cutting quality and established a prediction model through multiple linear regression equations.

Several scholars have combined auxiliary technology with laser cutting to reduce the HAZ, inhibit oxidation, and further improve wood quality. Hernandez et al. (2010, 2011) studied the influence of dual gas jet-assisted wood laser cutting and explored the influence of airflow on the finish of the cutting surface. Then, they deeply studied the influence of single and double gas jets on the wood laser-cutting process and compared the influence of different auxiliary gases under different pressures on kerf cutting. Yang et al. (2019) studied the effect of water-jet assisted laser cutting on the width and surface morphology of wood. However, the interaction between laser energy and water produced a large amount of water vapor during water-assisted processing, which resulted in unintended chemical reactions that affected the wood surface quality.

To improve wood processing and reduce the burning damage of the HAZ on the kerf surface, a gas-guided laser processing method is proposed in this paper. This study analyzed the use of $\mathrm{He}$ gas and $\mathrm{N}_{2}$ gas for gas-assisted laser cutting and compared the gasassisted method to traditional laser processing methods. Through a single-factor test method, the influence of the added flame retardant and unsupported combustion gases on laser power, cutting speed, cutting width, and processing quality were analyzed. The feasibility of this technology's application in cutting surface protection and HAZ reduction is discussed, and guidance on effective practices for the industrial production process is given.

\section{EXPERIMENTAL}

\section{Principle of Gas-guided Laser Machining}

Due to the physical properties of wood, if the selection of laser-cutting processing parameters is not appropriate, instantaneous complete gasification cannot be achieved and oxidation of the cutting surface will occur at high temperatures (Shen and Zhao 2010; Zhao et al. 2016). Therefore, a pressurized gas must be used for assisted processing. Figure 1 shows the ablative processing system for gas-assisted wood laser processing with inert and unsupported combustion gases. Based on the principle of physical damping, the gas with a certain pressure $\left(P_{1}\right)$ and velocity was sprayed around the laser beam, and the static and unpressurized oxygen in the air was extruded from the periphery of the nozzle. The residual concentration did not support combustion and blocked the absorption of oxygen in the high temperature area of the workpiece surface, forming a specific gas isolation layer (MartínezConde et al. 2017). The subsequent experiments yielded the expected results. The added gases passed through the laser coaxial nozzle to form an airflow shield over the cutting area. The protection of the added gases greatly reduced residual heat, effectively reduced the HAZ, and kept the temperature in the processing area below wood ignition temperature. These conditions allowed for smaller kerf width, a precise incision, and no surface burning. 


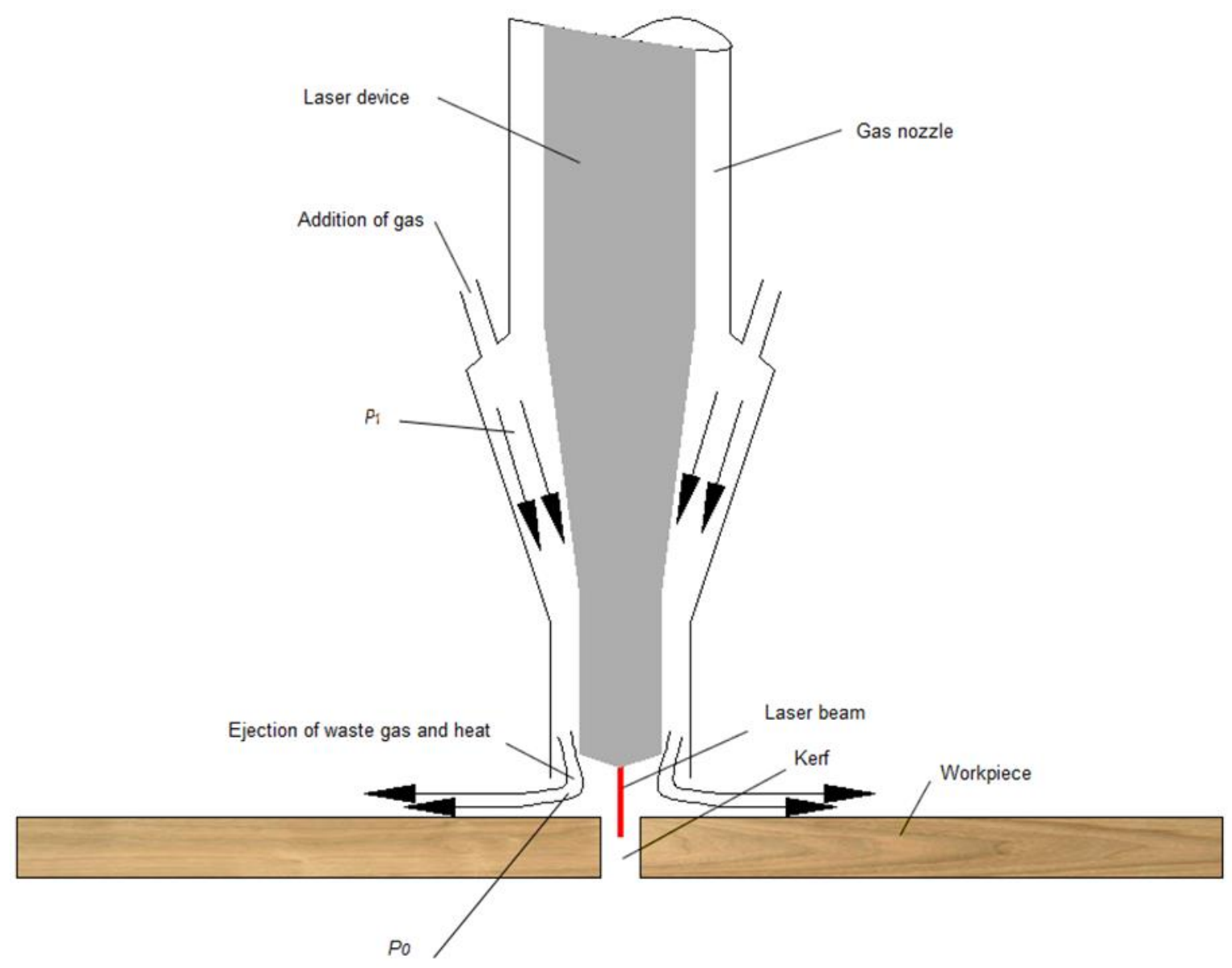

Fig. 1. Schematic diagram of gas-guided laser cutting

\section{Materials}

This experiment used cherry wood (Prunus serotina) as the raw material, which is a typical hardwood with mild wood properties, a loose fiber gap, and easy processability (Linsheng Machining Factory, Dongguan, China). It had an air-dry density of $0.85 \mathrm{~g} / \mathrm{m}^{3}$ and a moisture content of $10 \%$. The samples were obtained after processing, and the size was $100 \mathrm{~mm} \times 80 \mathrm{~mm} \times 0.2 \mathrm{~mm}$ (length $\times$ width $\times$ thickness $)$.

The laser processing systems contained a Nd:YAG (Neodymium Doped Yttrium Aluminum Garnet) laser (Dongjun Laser Co., Ltd., Chengdu, China). The wavelength of the laser was $1064 \mathrm{~nm}$, the pulse width was $20 \mathrm{~ns}$, and the pulse repetition rate ranged from $1 \mathrm{kHz}$ to $10 \mathrm{kHz}$. The experiment specified $3 \mathrm{kHz}$ to be used. A PH-LW06-BLP laser cooling system (Dongluyang Co., Ltd., Shenzhen, China) was used with an optical lens combination system (the focal length of the focusing lens was $100 \mathrm{~mm}$ and the focused beam spot size was $0.05 \mathrm{~mm}$ ).

The added gases were ejected from a coaxial supersonic nozzle (gas pressure was $0.2 \mathrm{MPa}$ and the gas flow rate was $5 \mathrm{~L} / \mathrm{min}$ ). Based on considerations of thermal conductivity, electronegativity, dissociation, and ionization energy, $\mathrm{N}_{2}$ gas and $\mathrm{He}$ gas were selected as the shielding gases. The quality of the cut section of the wood before and after gas-assisted protection was examined using a FEI Quanta200 scanning electron microscope (SEM, FEI Instruments, Hillsboro, OR, USA). 


\section{Process Method}

After placing the sample on the worktable, the laser beam entered the processing area through the feeding system through the reflection and focusing action of the optical system. The added gasses, which were supplied by the coaxial nozzle, were sprayed evenly on the surface of the sample. To ensure accuracy, a vertical fiber direction was used for linear cutting. The effects of laser power and cutting speed on the cutting width and the HAZ of the wood were investigated by group experiments with and without gas assistance. After the experiment was completed, the smoothness and cutting defects of cherry thin wood cut with and without gas assistance were observed by SEM. Table 1 shows the process parameters of the single factor experiment.

Table 1. Process Parameters of Single Factor Experiment

\begin{tabular}{|c|c|c|c|c|c|}
\hline Number & $\begin{array}{c}\text { Assisted } \\
\text { Gas }\end{array}$ & $\begin{array}{c}\text { Sample Size } \\
(\mathrm{mm} \times \mathrm{mm} \times \\
\mathrm{mm})\end{array}$ & $\begin{array}{c}\text { Laser } \\
\text { Wavelength } \\
(\mathrm{mm})\end{array}$ & $\begin{array}{l}\text { Laser Power } \\
\text { (W) }\end{array}$ & $\begin{array}{l}\text { Cutting } \\
\text { Speed } \\
(\mathrm{mm} / \mathrm{s})\end{array}$ \\
\hline 1 & Without & \multirow{2}{*}{$\begin{array}{c}100 \times 80 \times \\
0.2\end{array}$} & \multirow{2}{*}{1064} & \multirow{2}{*}{$\begin{array}{l}15,20,25 \\
30,40,50 \\
60, \text { and } 70\end{array}$} & \multirow{2}{*}{$\begin{array}{l}20,30,40 \\
50,60,70 \\
80 \text {, and } 90\end{array}$} \\
\hline 2 & With & & & & \\
\hline
\end{tabular}

\section{RESULTS AND DICUSSION}

\section{Effect of Laser Power and Cutting Speed on Cutting Width of Wood}

The process parameters were selected to cut samples of thin cherry wood, and the cutting widths under different laser power levels and cutting speeds were measured by digital microscope, $25 \times 10$ magnification (Supereyes Science and Technology Co., Ltd., Shenzhen, China). After laser cutting, the kerf edge after appeared slightly serrated. Therefore, the average of multiple measurements was calculated for each group of the kerf during measurement. Figure 2 shows the variation trends of the results.

Figure $2 \mathrm{~b}$ indicates that when the laser power was $P=60 \mathrm{~W}$ and the cutting speed was $V=20 \mathrm{~mm} / \mathrm{s}$, the kerf and the HAZ were larger. This result was attributed to the long interaction time between the laser beam and thin wood, which produced excessive heat that could not be absorbed and caused burning. Therefore, the cutting width increased, and the surface was seriously burnt. Figure $2 \mathrm{e}$ shows that when the cutting speed increased to $V=$ $50 \mathrm{~mm} / \mathrm{s}$, the cutting width decreased, the kerf quality improved notably, and the degree of burning reduced. This was consistent with the shorter interaction time between laser beam and wood. As the accumulation of heat per unit time applied to the wood surface by the laser was reduced, the burning speed of the wood at the kerf was lower than the moving speed of the laser. Therefore, the cutting width decreased accordingly, and the laser even failed to cut through the wood. Figure $2 \mathrm{~h}$ shows that when the cutting speed was $V=50$ $\mathrm{mm} / \mathrm{s}$ and the laser power was $P=15 \mathrm{~W}$, the kerf and the HAZ were smaller and the edge consistency was better. This was due to a reduction in the heat of the thin wood surface, which reduced gasification and combustion. However, the amount of wood removal was low. Therefore, the cutting width was small and surface burning was minor. Figure $2 \mathrm{f}$ shows that when the laser power increased to $P=40 \mathrm{~W}$, the kerf and the HAZ were larger and surface burning increased. This was attributed to an increase in power and the consequent heat accumulation on the surface of the thin wood. 
The rapid rise in temperature caused wood gasification to increase the cutting width. Therefore, the cutting width decreased with increased cutting speed and increased with increased laser power.

(a)
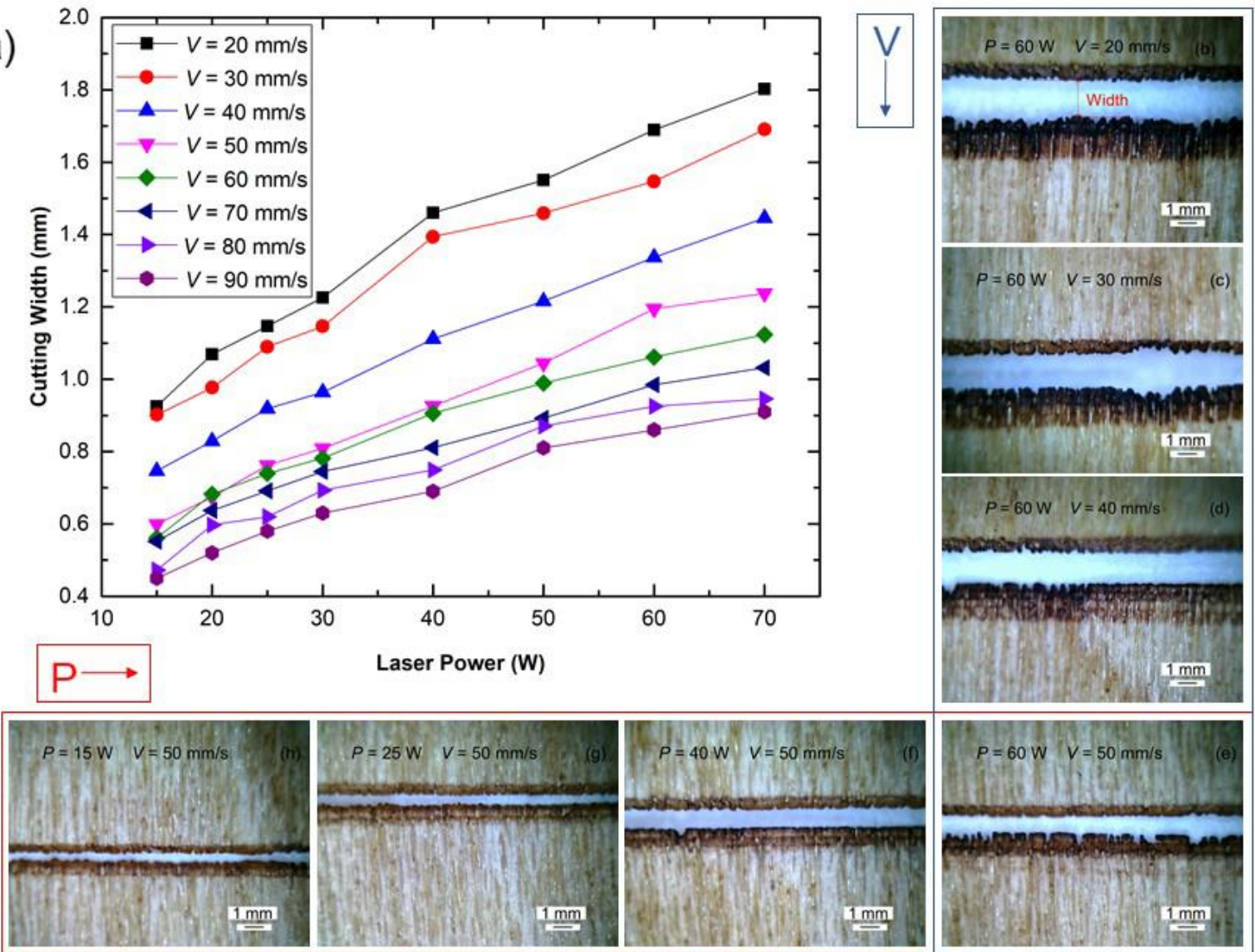

Fig. 2. (a) Effect of process parameters on cutting width; (b) $P=60 \mathrm{~W}, V=20 \mathrm{~mm} / \mathrm{s}$; (c) $P=60$ $\mathrm{W}, V=30 \mathrm{~mm} / \mathrm{s}$; (d) $P=60 \mathrm{~W}, V=40 \mathrm{~mm} / \mathrm{s}$; (e) $P=60 \mathrm{~W}, V=50 \mathrm{~mm} / \mathrm{s}$; (f) $P=40 \mathrm{~W}, V=50$ $\mathrm{mm} / \mathrm{s}$; (g) $P=25 \mathrm{~W}, V=50 \mathrm{~mm} / \mathrm{s}$; and (h) $P=15 \mathrm{~W}, V=50 \mathrm{~mm} / \mathrm{s}$

\section{Effect of Kerf Surface Quality of $\mathrm{N}_{2}$ gas}

To improve the kerf quality of laser-cut wood and reduce the burning caused by $\mathrm{HAZ}, \mathrm{N}_{2}$ gas-assistance was employed. Due to its inactive chemical properties and lack of combustion-supporting properties, $\mathrm{N}_{2}$ gas can greatly weaken the combustion-supporting effect of oxygen, and it is cheap and easily obtainable. The $\mathrm{N}_{2}$ gas blew off the residue, swept the surface, and cooled the cutting zone but was not directly used for cutting. Because it was the only unsupported combustion gas in contact with the workpiece, $\mathrm{N}_{2}$ could form an effective oxygen isolation protective layer on the processing surface and in the laser path range, which prevented the conditions necessary for wood combustion. Figure 3 shows the effect of cutting parameters on the width and surface quality of the kerf with or without $\mathrm{N}_{2}$ gas-assisted processing.

Figure 3 shows that the wood cutting width with $\mathrm{N}_{2}$ gas-assisted laser cutting was smaller than that of the wood cutting width without nitrogen-assisted cutting, and the degree of burning was reduced in the HAZ. This result was due to the combustible gas and oxygen being diluted with the added $\mathrm{N}_{2}$ gas, which reduced the concentration, slowed the reaction rate, and reduced the release of heat. Burning was avoided because of the inactivity 
and unsupported combustion chemical characteristics of $\mathrm{N}_{2}$ gas. Due to the quenching mechanism of unsupported combustion gas, the quenching ability of nitrogen was weaker than that of inert gas. Therefore, when $\mathrm{N}_{2}$ gas was added, the kerf edge still was serrated due to incomplete gasification during laser cutting. When the cutting speed was faster, the consistency of the whole cutting section was worse. This was due to the accumulation of heat from laser irradiation failing to reach the temperature required for complete gasification of wood when the cutting speed was higher. In addition, the density of $\mathrm{N}_{2}$ gas was less than that of the air, the injection rate was not high enough, or the pressure was low. Therefore, incomplete combustion occurred with the mixing of air during the working process, and the kerf surface was rough due to the air pressure that blew away the burning wood residue. Using $\mathrm{N}_{2}$ gas as an assistant gas for laser wood cutting did not improve kerf quality, reduce the HAZ, or reduce the occurrence of cauterization. $\mathrm{N}_{2}$ gas assistance was only effective for low speed cutting, and a high concentration was required.
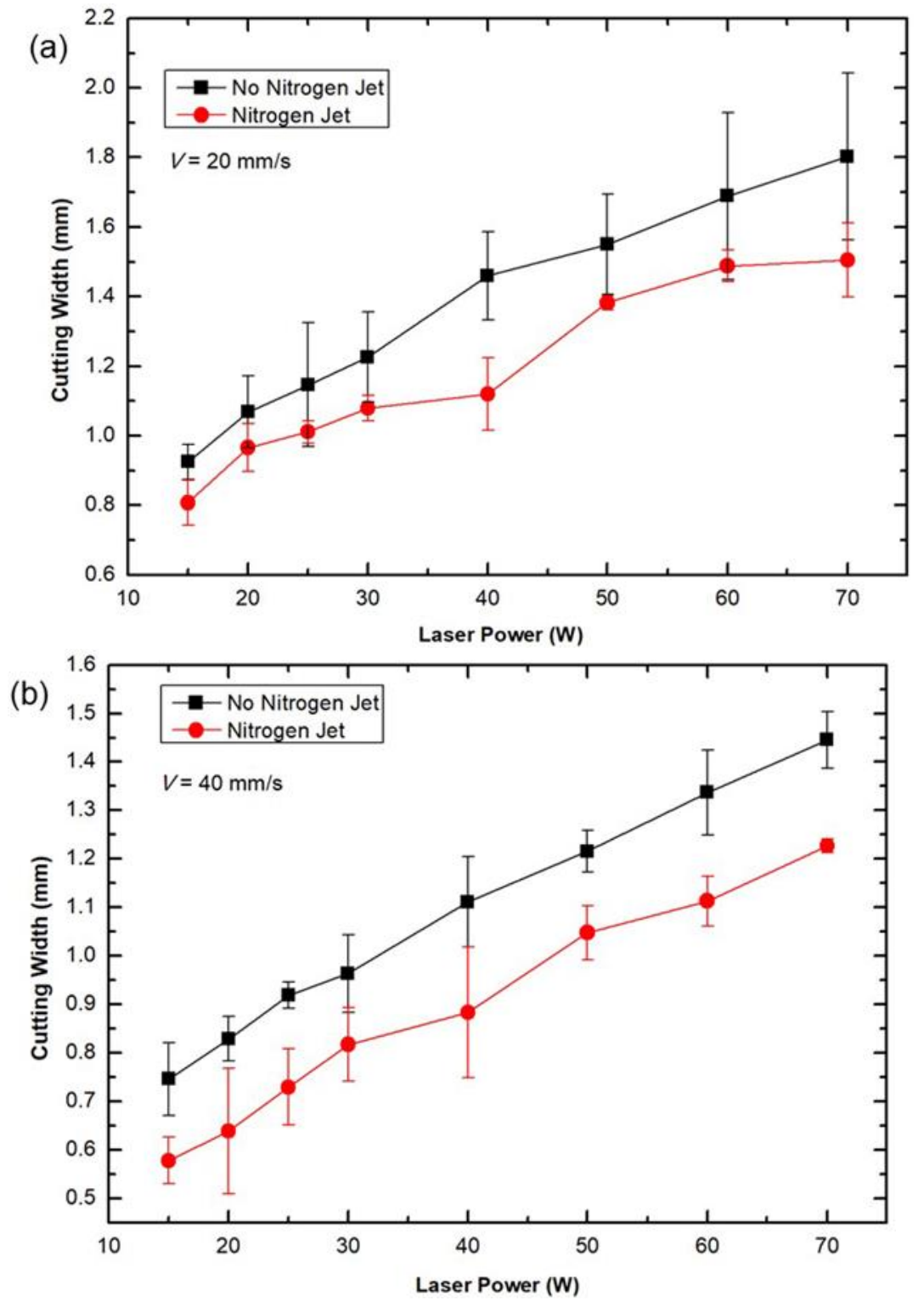

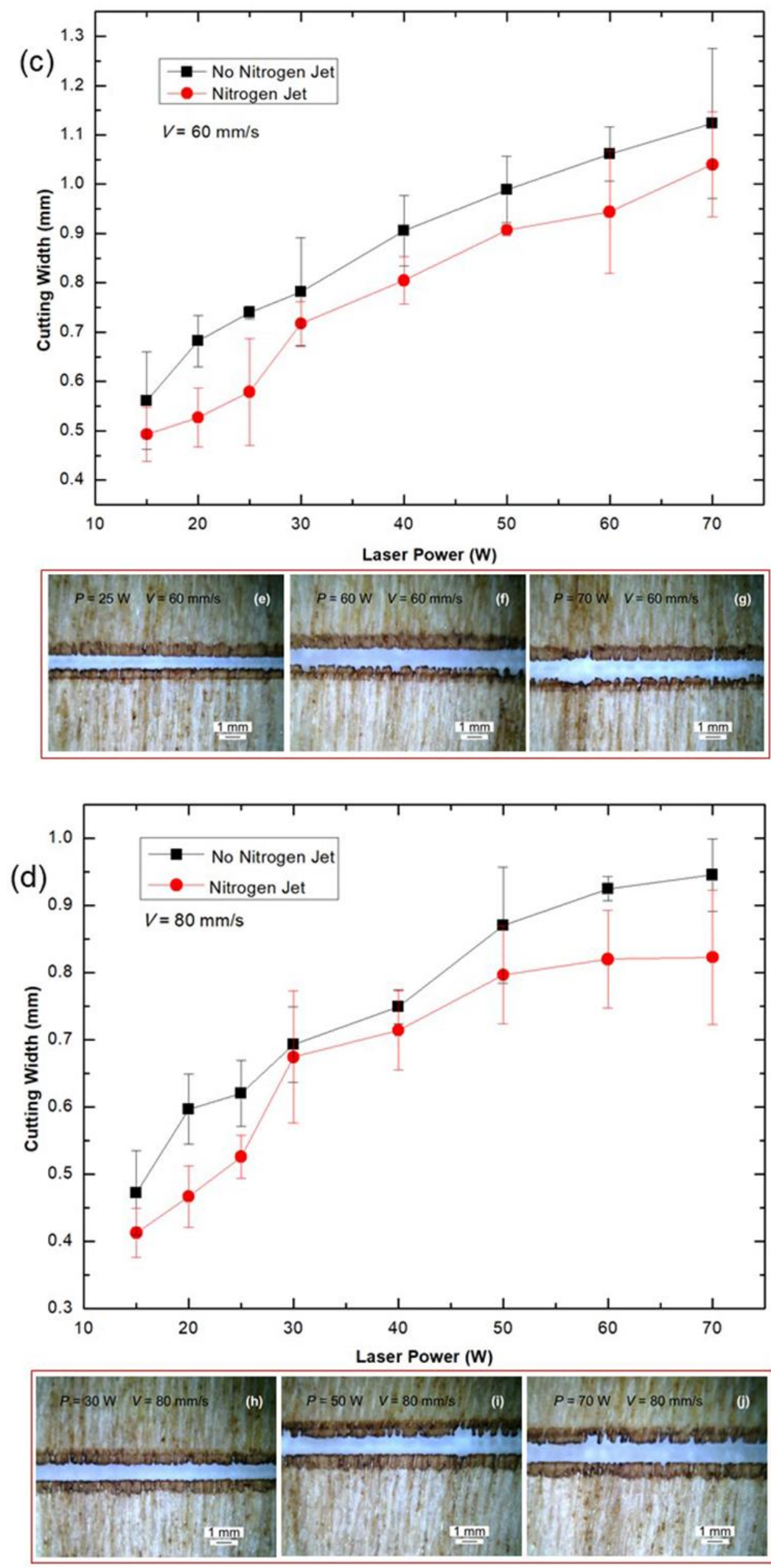

Fig. 3. Effect of processing parameters on cutting width with or without $\mathrm{N}_{2}$ gas assistance; (a) $V=$ $20 \mathrm{~mm} / \mathrm{s}$; (b) $V=40 \mathrm{~mm} / \mathrm{s}$; (c) $V=60 \mathrm{~mm} / \mathrm{s}$; (d) $V=80 \mathrm{~mm} / \mathrm{s}$; (e) $P=25 \mathrm{~W}, V=60 \mathrm{~mm} / \mathrm{s}$; (f) $P=$ $60 \mathrm{~W}, V=60 \mathrm{~mm} / \mathrm{s}$; (g) $P=70 \mathrm{~W}, V=60 \mathrm{~mm} / \mathrm{s}$; (h) $P=30 \mathrm{~W}, V=80 \mathrm{~mm} / \mathrm{s}$; (i) $P=50 \mathrm{~W}, V=80$ $\mathrm{mm} / \mathrm{s}$; and (j) $P=70 \mathrm{~W}, V=80 \mathrm{~mm} / \mathrm{s}$ 


\section{Effect of He gas on the Kerf Surface of Burning}

Although $\mathrm{N}_{2}$ gas had a flame-retardant effect, its quenching ability was weak, and the notch consistency decreased slightly due to incomplete combustion. To improve the degree of burning of the cutting surface, He gas was introduced as the assistant gas for laser processing, and the effect of its addition on the cutting width and burning degree was investigated. Figure 4 shows the effect of processing parameters on cutting width with or without He gas assistance.
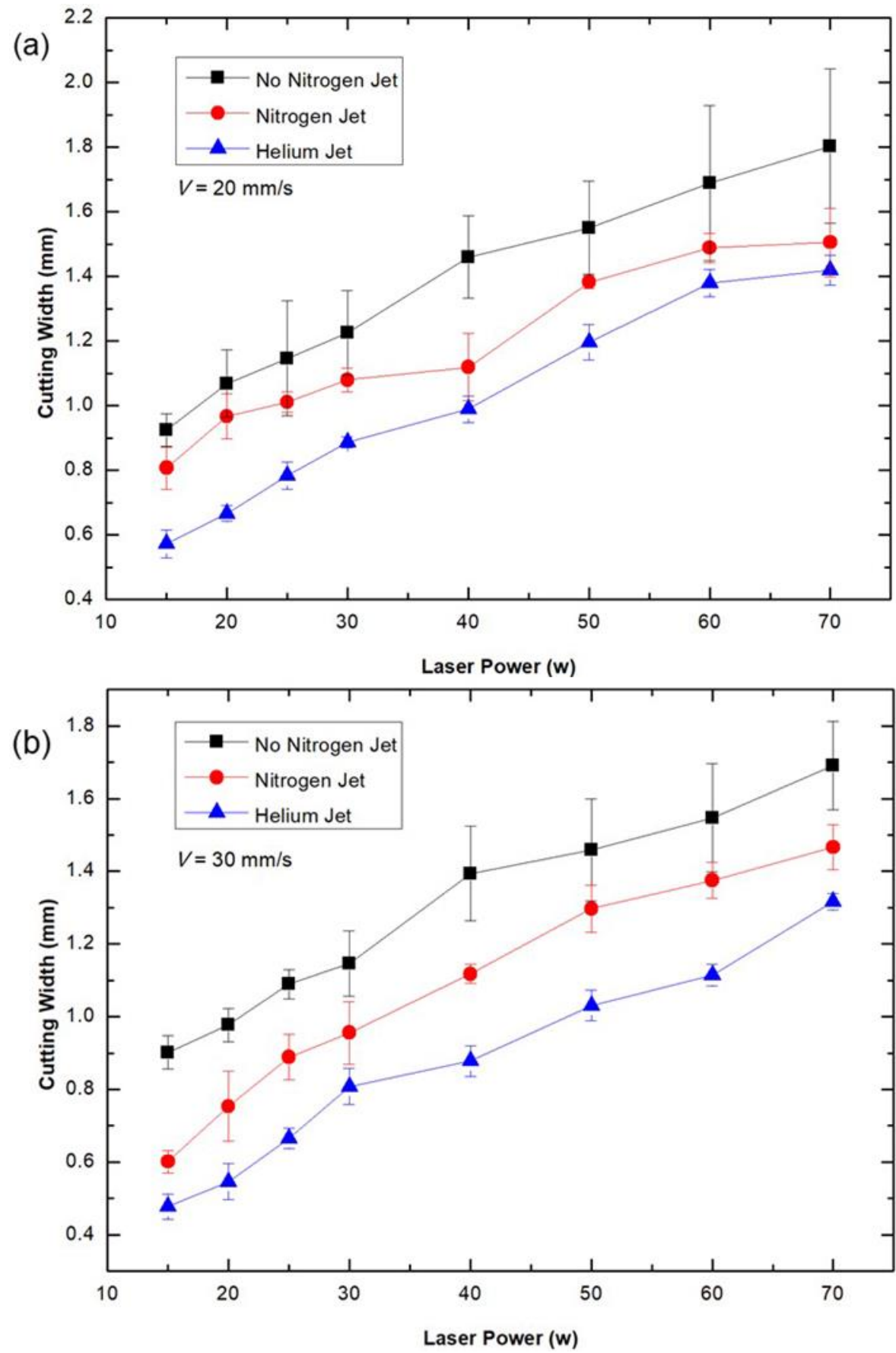

Fig. 4. Effect of processing parameters on cutting width with or without $\mathrm{He}$ assisted: (a) $V=20$ $\mathrm{mm} / \mathrm{s}$; (b) $V=30 \mathrm{~mm} / \mathrm{s}$ 
Figure 4 shows that under the same conditions, when using He gas assistance, the cutting width was less than when $\mathrm{N}_{2}$ gas assistance was used. This result was due to the pressure and flow rate of $\mathrm{He}$ gas being higher than the air in its natural state. The He gas pushed air through a narrow seam at the bottom, which led to the laser-cutting zone being in an anaerobic state. Air in its natural state did not enter the cutting area, and the air in the narrow seam working area was blown away by the laser beam and He gas flow with a certain pressure and velocity, which isolated the mixture of other gas. Therefore, the conditions necessary for wood burning were not met, and a flame-retardant effect was achieved.

During laser cutting, the heat of the contact surface was reduced by the purging of the flame retardant He gas flow with a certain pressure and flow rate, which prevented further heat diffusion. However, due to the isolated oxygen and the flame-retardant effect, the high temperature area could not burn and cauterize to ensure kerf smoothness and incision consistency. Because it is the inert gas with the best quenching effect, He gas effectively reduced the HAZ and impeded burning. Figure 5 shows the effect on the kerf surface burning with and without He gas assistance.

The HAZ of laser-cut wood refers to the area where cauterization and carbonization occur on both sides of the kerf due to the laser. As the width of the cauterization zone varied, three points were selected to measure the cauterization zone on both sides of the kerf, and the average value was taken.

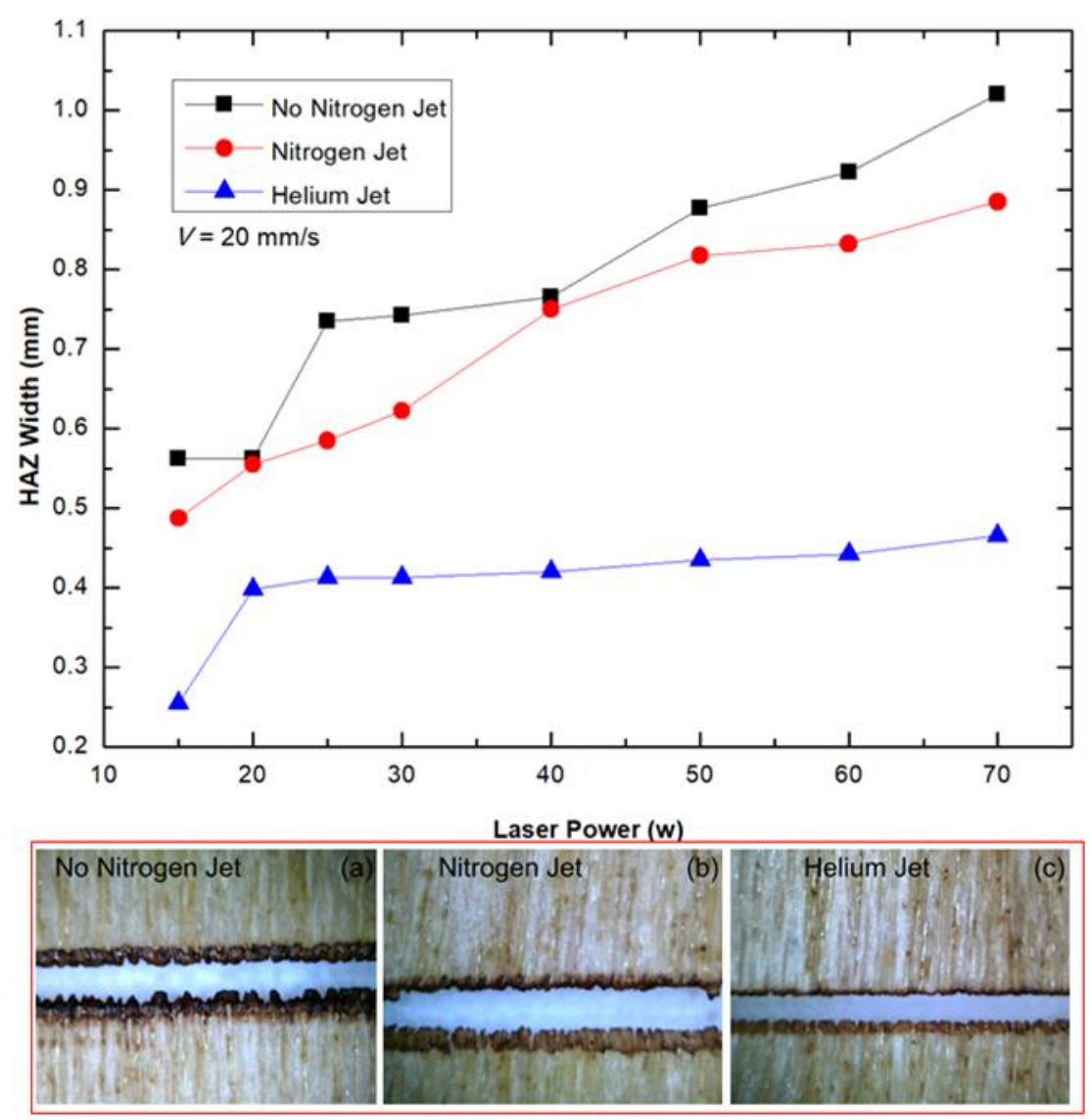



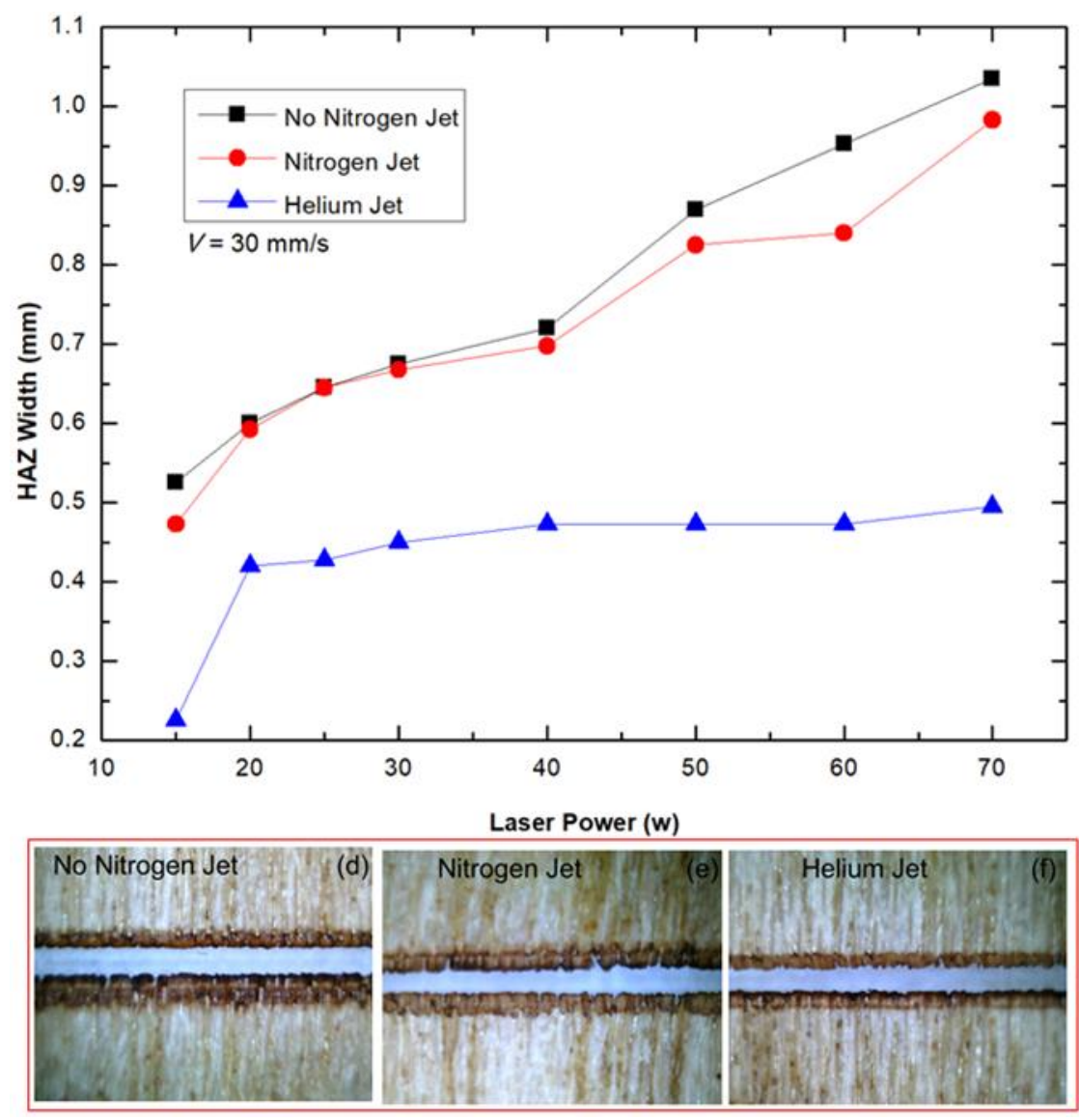

Fig. 5. Effect of He gas assistance on the kerf surface; (a), (b), and (c) $P=20 \mathrm{~W}, V=20 \mathrm{~mm} / \mathrm{s}$; (d), (e), and (f) $P=30 \mathrm{~W}, V=20 \mathrm{~mm} / \mathrm{s}$

Figure 5 shows that the HAZ was large for the traditional laser-cutting process, and the burning and carbonization of the kerf was severe. This was due to the workpiece being exposed to air during laser cutting and the high energy laser beam acting on the surface of the workpiece. Therefore, the wood instantly reached its ignition point and the oxygenassisted combustion in the air expanded the HAZ, which resulted in ablation and carbonization. Using He gas as a flame retardant for laser cutting resulted in a small HAZ, and only slight burning occurred, even at low cutting speeds. As the He, which was ejected from the coaxial protection nozzle, had a better quenching effect, it protected the area around the kerf. Flame retardant gas was introduced to the cutting seam through a nozzle at high pressure and high speed, and a flame-retardant airflow field was formed between the nozzle exit, the workpiece, and the interior of the kerf. Oxygen isolation and cooling on the edge of the kerf effectively removed the heat from the ablation area, which had a flame retardant effect, prevented further heat transmission to the workpiece, prevented HAZ expansion, and reduced the surface carbon content of the kerf.

Using SEM to observe the microscopic morphology of the kerf, the degree of laser burning on the wood surface was investigated, which allowed for analysis of the damage morphology of the wood fiber. Figure 6a shows that after conventional laser processing, the residue was not blown away quickly enough without gas assistance. In addition, there was a large HAZ on the kerf, glazing occurred on the surface of the kerf, and many carbonized cauterized particles were observed on the inner wall of tracheids. Figure $6 \mathrm{~b}$ illustrates that the surface of the kerf was fractured due to incomplete combustion, and the 
fibrous tissue near the kerf was rough and had many carbonized particles. In Fig. 6c, which depicts the process of wood gasification by flame retardant He gas-assisted laser cutting, the surface of the kerf was relatively smooth without obvious defects, and few particles were found in the inner wall of tracheids. This was due to the cooling effect of the inert gas reducing the temperature of the surface of the kerf and the airflow blowing the residue away from the processing area, which blocked the transmission of heat. Further, the oxygen isolation of the inert gas prevented the temperature from reaching the ignition point, which ensured the quality of the kerf.
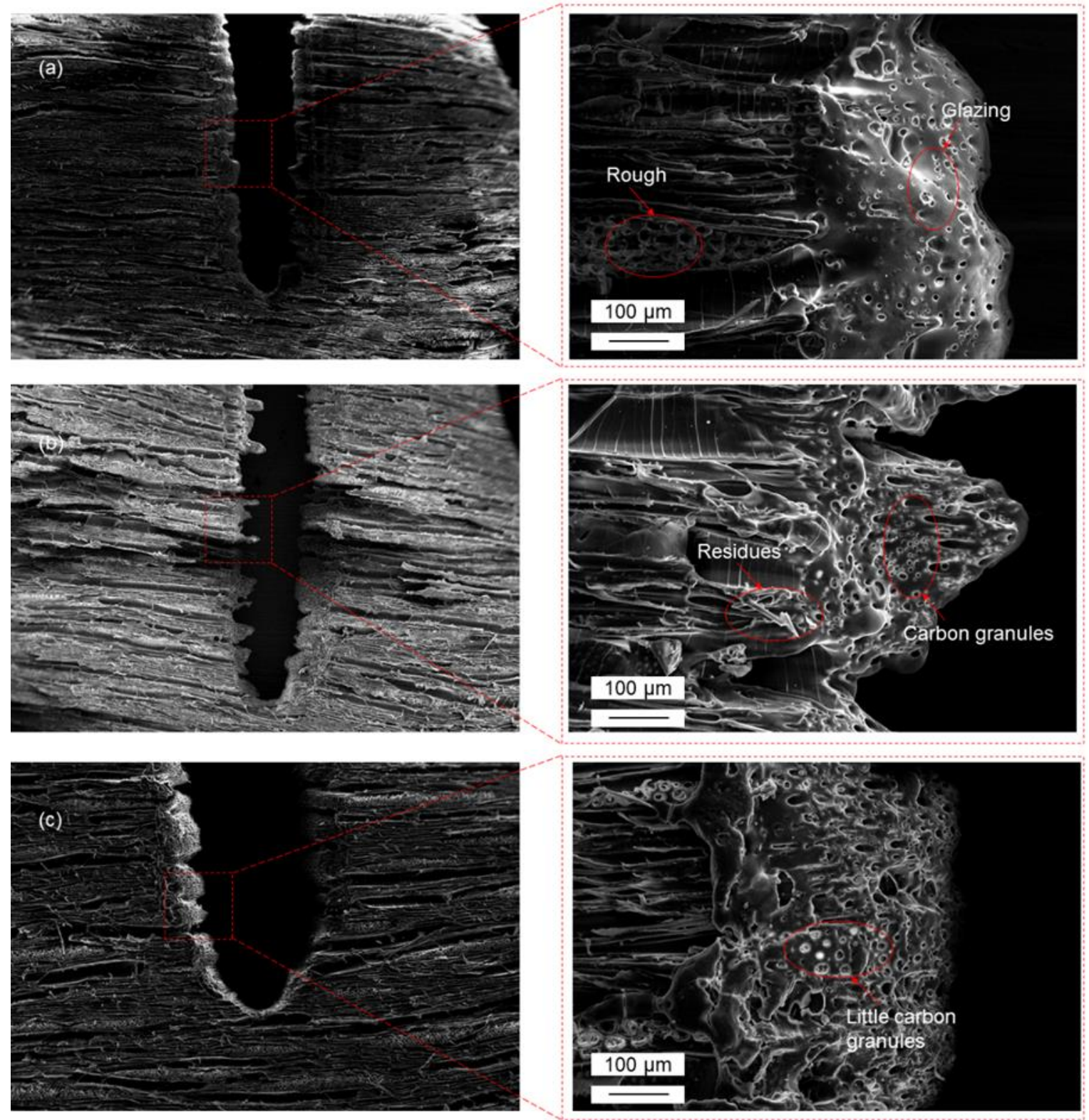

Fig. 6. Microtopography of cutting kerf (a) without gas, (b) with $\mathrm{N}_{2}$ gas assist, and with (c) He gas assist 


\section{CONCLUSIONS}

This study provided a new process for laser cutting micron-thin wood through the introduction of unsupported combustion gas and inert gas. Traditional non-gas-guided laser processing, unsupported combustion $\mathrm{N}_{2}$ gas-guided laser processing, and flame retardant He gas-guided laser processing were investigated. The effects of different process parameters on the cutting width, cut quality, HAZ, and surface burning were explored to improve wood processing quality.

1. When the micron-thin wood was processed with the traditional non-gas-guided lasercutting method, cutting width and kerf quality were directly affected by the laser power and cutting speed. Cutting width and cutting speed were approximately inversely proportional.

2. The cutting width of wood processed with the $\mathrm{N}_{2}$ gas guided laser method was less than that of traditional laser processing. However, due to the low density of $\mathrm{N}_{2}$ gas, the quenching ability was weak. Therefore, the kerf surface was affected by airflow, which resulted in incomplete combustion, a serrated appearance, and poor surface quality.

3. Cutting width decreased sizably when flame retardant He gas was added during laser cutting. In addition, the burning area on the kerf surface improved due to the flame retardant and cooling effects of the He gas. The surface quality was also notably improved, as the SEM images revealed a smooth and high quality cutting surface.

\section{ACKNOWLEDGMENTS}

The authors are grateful for the Fundamental Research Funds for the Central Universities (No. 2572019AB23) and the support of the Applied Technology Research and Development Project in Heilongjiang Province of China (No. GA19A402)

\section{REFERENCES CITED}

Barcikowski, S., Koch, G., and Odermatt, J. (2006). "Characterisation and modification of the heat affected zone during laser material processing of wood and wood composites," Holz als Roh- und Werkstoff 64(2), 94-103. DOI: 10.1007/s00107-005-0028-1

Eltawahni, H. A., Olabi, A. G., and Benyounis, K. Y. (2011). "Investigating the $\mathrm{CO}_{2}$ laser cutting parameters of MDF wood composite material," Optics \& Laser Technology 43(3), 648-659. DOI: 10.1016/j.optlastec.2010.09.006

Fukuta, S., Nomura, M., Ikeda, T., Yoshizawa, M., Yamasaki, M., and Sasaki, Y. (2016). "UV laser machining of wood," European Journal of Wood and Wood Products 74(2), 261-267. DOI: 10.1007/s00107-016-1010-9

Gaff, M., Razaei, F., Sikora, A., Hýsek, S., Sedlecký, M., Ditommaso, G., Corleto, R., Kamboj, G., Sethy, A., Vališ, M., and Ripa, K. (2020). "Interactions of monitored factors upon tensile glue shear strength on laser cut wood," Composite Structures 234, 1-10. DOI: 10.1016/j.compstruct.2019.111679.

Gurau, L., and Petru, A. (2018). "The influence of $\mathrm{CO}_{2}$ laser beam power output and scanning speed on surface quality of Norway maple (Acer platanoides)," 
BioResources 13(4), 8168-8183. DOI: 10.15376/biores.13.4.8168-8183

Hovikorpi, J., Laakso, P., Salminen, A., Miikki, N., and Kujanpää, V. (2004). "Laser cutting of birch pulp," Welding in the World 48(3-4), 6-13. DOI:

10.1007/BF03266420

Hernandez-Castaneda, J. C., Sezer, H. K., and Li, L. (2010). "Dual gas jet-assisted fibre laser blind cutting of dry pine wood by statistical modelling," International Journal of Advanced Manufacturing Technology 50(1-4), 195-206. DOI: 10.1007/s00170009-2491-Z

Hernandez-Castaneda, J. C., Sezer, H. K., and Li, L. (2011). "Single and dual gas jet effect in Ytterbium-doped fibre laser cutting of dry pine wood," The International Journal of Advanced Manufacturing Technology 56(5-8), 539-552. DOI: 10.1007/s00170-011-3209-6

Jiang, X., Li, J., Bai, Y., Wu, Z., Yang, C., and Ma, Y. (2016). "Laser cutting wood test and influencing factors of processing quality," Laser \& Optoelectronics Progress 53(3), 134-138. DOI: 10.3788/lop53.031403

Li, R., Xu, W., Wang, X., and Wang, C. (2018). "Modeling and predicting of the color changes of wood surface during $\mathrm{CO}_{2}$ laser modification," Journal of Cleaner Production 183, 818-823. DOI: 10.1016/j.jclepro.2018.02.194

Martin, M. Z., Labbé, N., Rials, T. G., and Wullschleger, S. D. (2005). “Analysis of preservative-treated wood by multivariate analysis of laser-induced breakdown spectroscopy spectra," Spectrochimica Acta Part B: Atomic Spectroscopy 60(7-8), 1179-1185. DOI: 10.1016/j.sab.2005.05.022

Martínez-Conde, A., Krenke, T., Frybort, S., and Müller, U. (2017). "Review: Comparative analysis of $\mathrm{CO}_{2}$ laser and conventional sawing for cutting of lumber and wood-based materials," Wood Science and Technology 51(4), 943-966. DOI: 10.1007/s00226-017-0914-9

Naderi, N., Legacey, S., and Chin, S. L. (1999). "Preliminary investigations of ultrafast intense laser wood processing," Forest Products Journal 49(6), 72-76.

Shen, J. Y., and Zhao, Y. (2010). "FEM simulation technologies of laser cutting wood board based on ANSYS," Advanced Materials Research 956(229), 1629-1631. DOI: 10.4028/www.scientific.net/amr.113-116.1629

Yang, C., Jiang, T., Yu, Y., Bai, Y., Song, M., Miao, Q., Ma, Y., and Liu, J. (2019). "Water-jet assisted nanosecond laser microcutting of northeast China ash wood: Experimental study," BioResources 14(1), 128-138. DOI: 10.15376/biores.14.1.128138

Yang, C., Jiang, T., Yu, Y., Dun, G., Ma, Y., and Liu, J. (2018). "Study on surface quality of wood processed by water-jet assisted nanosecond laser," BioResources 13(2), 3125-3134. DOI: 10.15376/biores.13.2.3125-3134

Zhao, H., Liu, Y., Sun, Y., Le, L., and Wu, J. (2016). "Effects of parameters of laser cutting on the cutting seam efficiency of Pinus sylvestris wood," Journal of Nanjing Forestry University (Natural Sciences Edition) 40(6), 203-206. DOI: 10.3969/j.issn.1000-2006.2016.06.032

Article submitted: Feb. 12, 2020; Peer review completed: April 11, 2020; Revised version received and accepted: May 18, 2020; Published: May 21, 2020.

DOI: $10.15376 /$ biores. 15.3.5366-5378 